\title{
Biodegradação de água residuária têxtil in natura por fungo em reator de leito fixo fluxo continuo
}

\section{Biodegradation of in nature textile wastewater for fungi fixex bed flow continuous reactor}

Data de entrada: 02/05/2017

Data de aprovação: 09/01/2018

Márcia Gabrielle Apolinario*/Barbara Barbosa Aguiar Chaves/Kelly de Araújo Rodrigues Pessoa/ Germana Maria Marinho Silva/Gloria Maria Marinho Silva

DOI: $10.4322 /$ dae.2019.010

Resumo

A indústria têxtil produz volumes elevados de efluentes, que devido às suas características resultam em impactos negativos ao meio ambiente, principalmente nos sistemas aquáticos. Assim, é de suma importância que recebam tratamento adequado capaz de torná-los inócuos ao meio ambiente. Nesta pesquisa, o fungo Phanerochaete chrysosporium foi imobilizado em reator de fluxo contínuo, com tempo de retenção hidráulica de 12 h, a fim de degradar efluente têxtil in natura a $75 \%$, contendo o corante índigo, e concentração de matéria orgânica. A remoção de cor de modo geral foi superior a $85 \%$, e matéria orgânica mensurada em termos de DQO total e solúvel foram superiores a $80 \%$. Em relação aos compostos nitrogenados, o nitrato obteve eficiência máxima de remoção e amônia e nitrito obtiveram eficiências de forma geral, 50\% e 80\%, respectivamente. $\mathrm{O}$ sistema empregado foi capaz de remover a cor do efluente in natura e matéria orgânica, sendo necessária maior otimização e estudos a fim de aumentar a eficiência do reator biológico empregado.

Palavras-chave: Corante, Biotratamento, Phanerochaete chrysosporium.

\section{Abstract}

The textile industry produces large volumes of wastewater, which due to their characteristics results in negative impacts to the environment, especially in aquatic systems. Thus, it is of paramount importance that they receive treatment able to make them harmless to the environment. In this research, the fungus Phanerochaete chrysosporium, was immobilized in a flow reactor still with hydraulic retention time of 12 hours, adding textile effluent to 75\%, containing the dyes indigo carmine, and concentration of organic matter. Removal of color was generally superior to $85 \%$ and organic matter, measured in terms of total and soluble COD were above $80 \%$. In relation to the nitrogenous compounds, nitrate achieved maximum removal efficiency and ammonia and nitrite obtained generally efficiencies $50 \%$ and $80 \%$, respectively. The system employed was capable of removing the color in natura effluent and organic matter, requiring further optimization, and studies to increase the efficiency of the biological reactor employed. Keywords: Dye. Biotreatment, Phanerochaete chrysosporium.

Márcia Gabrielle Apolinario - Mestre em Gestão Ambiental

Barbara Barbosa Aguiar Chaves - Doutora em Saneamento Ambiental (UFC). Professora do Instituto Federal do Maranhão.

Kelly de Araújo Rodrigues Pessoa - Doutora em Hidráulica e Saneamento (USP). Professora doMestrado em Tecnologia e Gestão Ambiental do Instituto Federal do Ceará.

Germana Maria Marinho Silva - Mestre em Tecnologia e Gestão Ambiental (IFCE). Professora dolnstituto Federal do Ceará.

Gloria Maria Marinho Silva - Doutora em Hidráulica e Saneamento (USP). Professora do Mestrado emTecnologia e Gestão Ambiental do Instituto Federal do Ceará.

"Endereço para correspondência: Rua Oswaldo Studart, 101, Iguape-Aquiraz-Ceará. CEP: 61700-000. Telefone: (85) 986075205. E-mail: gabriellemgaagmail.com. 


\section{INTRODUÇÃO}

A indústria têxtil consome grandes quantidades de água potável e, consequentemente gera volume elevado de efluente, o qual é rico em corantes e outros produtos químicos decorrente do processo de beneficiamento do tecido, resultando em impactos negativos nos ecossistemas aquáticos, quando lançados sem tratamento adequado.

O descarte do efluente têxtil promove sérios problemas decorrentes da presença dos corantes e de seus subprodutos, constituindo assim uma ameaça ao meio ambiente em muitos lugares do planeta. A coloração do efluente têxtil afeta esteticamente o corpo hídrico, além de causar danos aos seres vivos aquáticos, pois impede a penetração da luz prejudicando o processo de fotossíntese, bem como provoca a eutrofização do sistema aquático pelo acúmulo de nutrientes (GAJERA, 2015; OZDEMIR et al., 2013; FRANCA et al., 2015).

Anualmente são produzidos de 600 a700 mil toneladas de corantes têxteis sintéticos, que são responsáveis por gerar cerca de 6,6 milhões de dólares em venda no mundo (FOURCADE et al. 2013). O Banco Mundial estima que de 17 a 20\% da poluição proveniente de efluentes industriais vem da indústria têxtil (KANT, 2012). Essas indústrias consomem cerca de $200 \mathrm{~L}$ de água para produzir cerca de $1 \mathrm{~kg}$ de tecido (GHALY et al. 2014).

De acordo com Kaushik \& Malik (2009), os efluentes das indústrias têxteis e da produção de corantes, em comparação com outros efluentes industriais, são os mais difíceis de tratar devido à presença de corantes sintéticos e de estruturas aromáticas complexas, que lhes conferem uma elevada estabilidade e consequentemente recalcitrância para biodegradação.

O desenvolvimento de tecnologias para o tratamento dos efluentes provenientes da indústria têxtil está sendo um desafio nas últimas décadas para as indústrias, pois o método de tratamento escolhido depende das características do efluente gerado, uma vez que existe uma diversidade de corantes e variações nos tipos de processo das diferentes indústrias têxteis.

Os efluentes têxteis podem ser tratados por métodos físicos, físico-químicos, químicos e biológicos. Os tratamentos físicos não degradam as substâncias presentes no efluente, apenas as transferem de uma fase para outra, necessitando de pós-tratamento. Entretanto, são eficazes na remoção da cor para pequenos volumes. No tocante às tecnologias à base de processos físicoquímicos, estas apresentam restrições devido ao seu custo elevado, à formação de produtos perigosos, ou intensas exigências de energia (KANG et al. 2010). Com relação aos métodos biológicos empregando bactérias e fungos, são considerados alternativas promissoras, pois possuem menor custo e são ecologicamente sustentáveis na degradação de corante e remoção de cor. No entanto, os subprodutos da descoloração anaeróbia, como as aminas aromáticas, podem inibir, em larga escala, a atividade das bactérias (QU et al. 2010). Em contraste, os fungos da podridão branca têm demonstrado potencial na degradação de inúmeros corantes (GIARDINA et al, 2010).

O grande potencial dos fungos da podridão branca está relacionado ao seu sistema enzimático inespecífico. De acordo com Kamida et al (2005), fungos basidiomicetos da podridão branca, degradadores de lignina, são eficazes na degradação de vários compostos poluentes e possuem elevado potencial na remediação de áreas contaminadas. A produção de enzimas não específicas por estes fungos da podridão branca, tais como lignina peroxidase (LiP), manganês peroxidase (MnP) e lacase (YANG et al. 2009), oxida compostos resistentes aos ataques microbianos e são capazes de quebrar uma variedade de ligações moleculares heterogêneas (CHANDER e ARORA, 2007), resultando em uma maior interação física e enzimática com o ambiente e a tolerância às altas concentrações de componentes xenobióticos.

As vantagens de utilizar fungos da podridão branca estão na sua capacidade de não requererem pré- 
-condicionamento para poluentes específicos; na secreção de suas enzimas dependente da limitação de nutrientes (nitrogênio e carbono) do que mesmo da presença de poluentes e de seus sistemas de enzimas extracelular capazes de suportar elevadas concentrações de poluente (KAPDAN et al. 2000).

A descoloração de corantes sintéticos por fungos da podridão branca é mais eficiente, possui baixo custo, é ecologicamente sustentável quando comparada às outras técnicas, e uma promissora alternativa em relação aos métodos tradicionais para a degradação de corantes (COUTO, 2009).

O índigo sintético ( $\mathrm{Cl}$ Vat Blue I) é muito utilizado na indústria têxtil para tingir jeans e é reconhecido por se tratar de um composto quimicamente estável, sendo a biodegradação dificultada por sua estrutura molecular (Figura 1) de grande complexidade (ALMEIDA et al. 2012). Por ser um corante a cuba, requer uma etapa de redução em meio alcalino $(\mathrm{pH}$ 11-14) para se tornar solúvel em água. O ditionito de sódio (Na2S2O4) é o agente redutor mais utilizado, entretanto o mesmo cria problemas devido à formação de produtos em seus efluentes, tais como sulfitos, sulfatos (BOZIC, 2008).

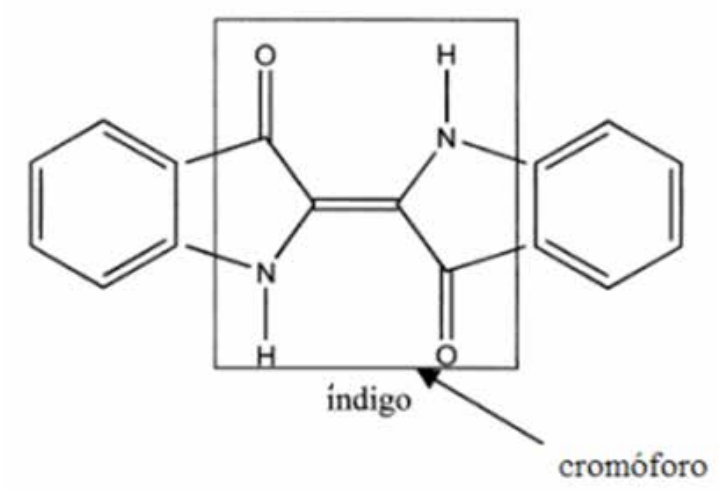

Fonte: adaptado de Vautier et al., (2001).

Assim sendo, esta pesquisa teve como objetivo geral avaliar o potencial do fungo Phanerochaete chrysosporium, imobilizado em um reator de fluxo contínuo ascendente, em degradar efluente têxtil in natura.

\section{OBJETIVO}

Esta pesquisa foi desenvolvida com o propósito de degradar efluente têxtil in natura a $75 \%(\mathrm{v} / \mathrm{v})$, a fim de se obter um efluente final clarificado e com baixa concentração de DQQO e de nutrientes nitrogenados.

\section{MATERIAIS E MÉTODO}

\subsection{Caracterizações do efluente}

A água residuária in natura foi coletada, semanalmente, de uma indústria têxtil localizada no município de Maracanaú-CE, do tanque de equalização, por um período de três meses, sendo a mesma caracterizada por intensa coloração azul, devido à presença do corante Índigo.

As análises físico-químicas determinadas foram: Demanda Química de Oxigênio bruta e filtrada (DOO), amônia e nitrito, executadas de acordo com APHA (2005); e nitrato de acordo com Rodier (1975).

A determinação da concentração de corante foi estimada usando um espectrofotômetro UV-Vis modelo Thermo ScientificTM Evolution 60S -, com a leitura em absorbância ( $\lambda: 660 \mathrm{~nm})$, por meio de curva de calibração construída a partir dos padrões com concentrações conhecidas do corante (DyStar@ Indigo Vat dye 40\% Solution) nas concentrações de 0,5, 1, 5, 10, 15, 20, 30 e $50 \mathrm{mg}^{\mathrm{L} \mathrm{L}^{-1}}$ ) versus absorbâncias (RODRIGUES et al., 2011).

\subsection{Inóculo}

A espécie Phanerochaete chrysosporium foi cultivada em placas de Petri esterilizadas em autoclave a $121^{\circ} \mathrm{Ce} 1 \mathrm{~atm}$, durante $20 \mathrm{~min}$. Posteriormente as placas receberam $15 \mathrm{~mL}$ do meio de cultura com a seguinte composição (g. $\left.\mathrm{L}^{-1}\right)$ : extrato de levedura $(2,0)$, glicose $(20,0), \mathrm{K} 2 \mathrm{HPO} 4(1,0), \mathrm{KH} 2 \mathrm{PO} 4(0,6)$, MgSO4 $(0,5)$, peptona $(2,0)$ e ágar $(18,0)$. 
As placas foram mantidas sob $28^{\circ} \mathrm{C}$ em incubadora microbiológica, durante sete dias. Após esse período, os esporos foram removidos com uso de solução salina a $0,9 \%$ de $\mathrm{NaCl}$, acrescida de $80 \mu \mathrm{L}$ Tween 80, formando uma lâmina liquida e favorecendo a sua raspagem com o auxílio de Alça de Drigalski e transferidos para tubos de ensaio.

Para contagem dos esporos foi preparada uma solução utilizando $50 \mu \mathrm{L}$ da suspensão de esporos, previamente agitada em agitador tipo Vórtex, acrescido de $950 \mu \mathrm{L}$ de solução salina com Tween 80 , resultando em diluição de 1:20.

Posteriormente, $20 \mu \mathrm{L}$ da solução preparada foram transferidos para uma câmara de Neubauer a fim de proceder à contagem dos esporos em microscópio óptico da marca Opton com aumento de 400x. Para o cálculo do número de esporos foi empregada a Equação 1, descrita por Sampaio (2005).

$\mathrm{C}($ esporos $/ \mathrm{ml})=\mathrm{N}$ *diluição*V $\quad$ Equação 1

Sendo:

C: concentração de esporos $/ \mathrm{mL}$

$\mathrm{N}$ : Média da soma dos quadrantes de esporos contados

V: volume da Câmara de Neubauer (2.5 x 105 ml)

\subsection{Imobilização da biomassa no reator}

A espécie Phanerochaete chrysosporium foi imobilizada em espuma de poliuretano, cortada em cubos de $1 \mathrm{~cm}$ de aresta, num total de $40 \mathrm{~g}$ de espuma. Cinco gramas de espuma previamente esterilizada foram colocados em redes de polietileno e, em seguida, dentro de baleiros, com volume útil de $2 \mathrm{~L}$, contendo meio nutritivo com macro e micronutrientes. A inoculação do fungo foi realizada próxima ao bico de Bunsen, a fim de evitar contaminação, e a concentração da suspensão de esporos utilizada foi de $2 \times 106$ esporos.mL-1. A concentração foi determinada por estar acima de 103 esporos $/ \mathrm{mL}$, o que favorece o maior consumo de carboidrato e nitrogênio (RODRIGUES e MARINHO, 2012).

O meio nutritivo com macro nutriente teve a seguinte composição $\left(\mathrm{g} \cdot \mathrm{L}^{-1}\right)$ : glicose $(5,0), \mathrm{NaNO}_{3}$ $(0,25), \mathrm{MgSO}_{4} \cdot 7 \mathrm{H}_{2} \mathrm{O}(1,0), \mathrm{CaCl}_{2} \cdot \mathrm{H}_{2} \mathrm{O}(0,04),\left(\mathrm{NH}_{4}\right)-$ $2 \mathrm{SO}_{4}(0,5), \mathrm{KH}_{2} \mathrm{PO}_{4}(2,0), \mathrm{H}_{2} \mathrm{MoO}_{4}(0,02), \mathrm{MnSO}_{4}$ $(0,02), \mathrm{Fe}_{2}\left(\mathrm{SO}_{4}\right)_{3}(0,02)$ e $\mathrm{ZnSO}_{4} \cdot 7 \mathrm{H}_{2} \mathrm{O}(0,01)$.

Foram adicionados $10 \mathrm{ml} . \mathrm{L}^{-1}$ de solução de micronutrientes que continham em sua composição (g.t-1 $): \mathrm{MgSO}_{4} .7 \mathrm{H}_{2} \mathrm{O}(3,0), \mathrm{NaCl}(1,0), \mathrm{MnSO}_{4}$. $\mathrm{H}_{2} \mathrm{O}(0,5), \mathrm{FeSO}_{4} \cdot 7 \mathrm{H}_{2} \mathrm{O}(0,1), \mathrm{ZnSO}_{4} \cdot \mathrm{H}_{2} \mathrm{O}(0,1)$, Co$\mathrm{Cl}_{2} \cdot 6 \mathrm{H}_{2} \mathrm{O}(0,1), \mathrm{CaCl}_{2} \cdot 2 \mathrm{H}_{2} \mathrm{O}(0,082), \mathrm{H}_{3} \mathrm{BO}_{3}(0,01)$, $\mathrm{CuSO}_{4} \cdot 5 \mathrm{H}_{2} \mathrm{O}(0,01)$.

Os baleiros receberam aeração por meio de mini-compressores. A cada 72 h o meio de cultura era trocado, durante 14 dias, até a formação do biofilme na superfície do material suporte. Após esse período, a biomassa dos baleiros foi transferida para o reator biológico,que foi operado em regime de escoamento contínuo.

\subsection{Montagem e operação do reator biológico}

O reator utilizado durante o estudo está apresentado na Figura 2. Foi confeccionado em acrílico, com volume útil de $4 \mathrm{~L}$ e diâmetro interno de 100 $\mathrm{mm}$ e $80 \mathrm{~cm}$ de altura. A estrutura possuía dispositivos de entrada e saída da água residuária e também orifícios para entrada de ar, provida por mini-compressores, com $220 \mathrm{KW}$ de potência e vazão de aproximadamente 4,1 L.min-1. 0 tempo de detenção hidráulica (TDH) utilizado foi de $12 \mathrm{~h}$.

Ao longo do eixo longitudinal do reator foram colocados contentores, placas perfuradas de PVC, possuindo no centro passagem para uma haste em inox, fixada por encaixe no fundo do reator. A função dos contentores era a de evitar o descolamento do meio suporte e consequente arraste do reator. 
Figura 2 - Reator aeróbio de leito fixo e escoamento ascendente.

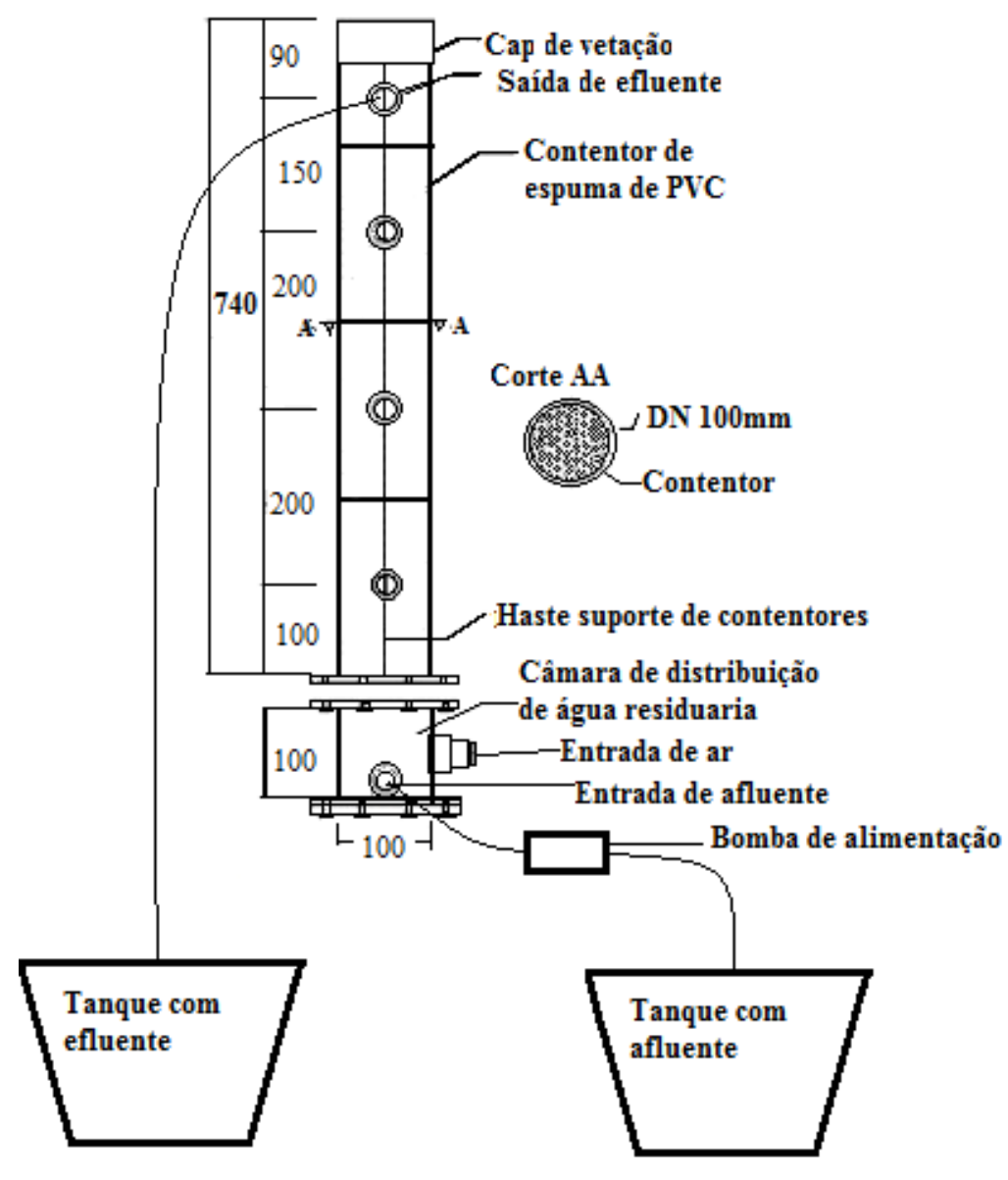

Fonte: Adaptado de Rodrigues (2006).

0 afluente que alimentou o reator foi preparado com $75 \%$ da água residuária in natura e $25 \%$ de água da torneira acrescida de macronutrientes (g.L-1 $): \mathrm{KH}_{2} \mathrm{PO}_{4}(0,2), \mathrm{MgSO}_{4} \cdot 7 \mathrm{H}_{2} \mathrm{O}(0,5)$, Ca$\mathrm{Cl}_{2} \cdot 2 \mathrm{H}_{2} \mathrm{O}(0,1)$ e glicose $(0,5)$ e de $10 \mathrm{~mL}$ de solução de micronutrientes e armazenado no tanque com afluente. Amostras do afluente e efluente do reator eram coletadas para o monitoramento. $\mathrm{O}$ afluente era armazenado em recipientes de $75 \mathrm{~L}$, e uma bomba peristáltica o enviava para o reator. $\mathrm{O} \mathrm{pH}$ da água residuária afluente ao reator era previamente ajustado para o valor de $5 \pm 0,05$ com ácido sulfúrico P.A. O reator foi operado por 46 dias e realizadas 20 coletas.

\subsection{Contagem de micro-organismo (fungos e bactérias)}

Ao final da operação do reator, amostras do biofilme foram submetidas ao procedimento de contagem do número de colônias de fungos e bactérias para determinação da predominância entre os mesmos.

A amostra do biofilme foi desprendida da espuma suporte utilizando-se $50 \mathrm{~mL}$ de água destilada estéril $\left(20^{\circ} \mathrm{C}\right.$, a $\left.1 \mathrm{~atm}\right)$ e pérolas de vidro em $\mathrm{Er}$ lenmayer por meio de agitação manual vigorosa. Posteriormente, $1 \mathrm{~mL}$ do conteúdo foi adicionado em um tubo com $9 \mathrm{~mL}$ de solução salina $(0,90 \%)$ 
o qual foi agitado em vórtex por 10 minutos. Nova alíquota de $1 \mathrm{~mL}$ foi transferida para novo tubo contendo a solução salina, os quais foram submetidos a agitação. Desse modo, foram obtidas diluições seriadas de $10^{-1}, 10^{-2}, 10^{-3}, 10^{-4}$ e $10^{-5}$. Seguidamente, $0,1 \mathrm{~mL}$ de cada diluição foi então adicionada às placas que continham meio específico para o crescimento de fungos ou de bactérias. Foi empregado para o crescimento de fungos o meio Martin e para o de bactérias o meio Nutriente-ágar, utilizando placas de Petri em duplicata.

O meio Martin apresentava a seguinte composição por litro de água destilada (g.L-1 ): $\mathrm{KH}_{2} \mathrm{PO}_{4}(1,0)$, peptona $(5,0), \mathrm{K}_{2} \mathrm{HPO}_{4}(0,5), \mathrm{MgSO}_{4} .7 \mathrm{H}_{2} \mathrm{O}(0,5)$, glicose $(10,0)$, extrato de levedura $(0,5)$, rosa bengala $(0,033)$ e ágar-ágar $(18,0)$. Já o meio nutriente-ágar foi preparado, adicionando-se por litro de água destilada $\left(\mathrm{g} \cdot \mathrm{L}^{-1}\right)$ : bacterioagar $(15,0)$, extrato de carne $(3,0)$, peptona $(5,0)$ e $\mathrm{NaCl}(8,0)$.

As placas para contagem do número de colônias de fungos e bactérias receberam $10 \mathrm{~mL}$, respectivamente, de meio Martin e Nutriente-ágar, e ainda $0,2 \mathrm{~mL}$ de cada diluição seriada, promovendo-se movimentos circulares na forma de um oito para homogeneizar o meio. Posteriormente, as placas foram vedadas, incubadas à temperatura de $\pm 28^{\circ} \mathrm{C}$. Todo o procedimento ocorreu em duplicata.

Após 48 h e 120 h, respectivamente, para bactérias e fungos, foram selecionadas placas que apresentaram número de colônias superior ou igual a 25 e inferior ou igual a 250, faixa ideal para facilitar a contagem (Tortora et al., 2000) que foi feita com auxílio de contador de colônias mecânico. A Equação 2 foi utilizada para obtenção do número de unidades formadoras de colônias por $\mathrm{mL}$ (UFC. $\mathrm{mL}^{-1}$ ), conforme APHA (2005).

UFC $/ \mathrm{mL}=$ no de colônias $* 5$ * inverso da diluição Equação 2

\subsection{Ensaio de adsorção do corante no biofilme}

Este ensaio foi realizado com o intuito de verificar a quantidade de corante presente no biofilme. Para este fim, um cubo contendo biomassa imobilizada foi retirado do reator e transferido para Erlenmeyer usando solução salina e pérolas de vidro. Em seguida, o conjunto foi submetido à agitação vigorosa para propiciar a remoção de biomassa do meio suporte.

O meio foi então centrifugado a 3500 rpm e o sobrenadante foi separado da biomassa. Metanol foi utilizado como solvente para remover o corante adsorvido, de modo que $10 \mathrm{~mL}$ do foram adicionados ao tubo contendo a biomassa, permanecendo em contato durante $20 \mathrm{~min}$. Depois deste período, foram adicionados mais $5 \mathrm{~mL}$ de metanol, seguido de homogeneização e centrifugação e leitura do sobrenadante em espectrofotométrica à $660 \mathrm{~nm}$ (ANDRADE, 2013).

\subsection{Ensaio de adsorção no meio suporte.}

Neste ensaio foi utilizado frasco de vidro de $4 \mathrm{~L}$, ao qual foram adicionados $12 \mathrm{~g}$ de cubos de espuma de poliuretano previamente secos em estufa. Este recipiente recebeu $3 \mathrm{~L}$ do efluente e de $0,5 \mathrm{~g} \cdot \mathrm{L}^{-1}$ de glicose e de micro e macronutrientes. A água residuária para o teste de adsorção foi preparada da mesma forma do afluente que alimentou o reator.

A capacidade máxima de adsorção do corante na espuma de poliuretano, empregada como material suporte, foi monitorada a partir da sua concentração inicial, no meio, durante um período de $2 \mathrm{~h}$ (ANDRADE, 2013).

\section{RESULTADOS}

Na Figura 3 está apresentada a variação da concentração de corante da água residuária a $75 \%$ na entrada e na saída do reator. Houve redução da concentração do corante ao longo de toda a operação do reator. A eficiência de degradação de corante foi superior a $80 \%$, com exceção da coleta 4 (72,23\%), 
coleta $5(51,94 \%)$ e coleta $8(73,24 \%)$ sendo a média de $89,19 \%$. A menor descoloração ocorrida nessas coletas provavelmente está associada às atividades da indústria, que podem ter apresentando uma concentração de corante bem acima da capacidade do fungo de tratar eficazmente no TDH estudado.

A elevada eficiência de remoção do corante provavelmente foi influenciada pelo uso de biomassa fúngica imobilizada, uma vez que nessa configuração a mesma se regenera e o reator pode ser reutilizado por vários ciclos e suportar cargas de efluentes com substâncias tóxicas (SOLIS, 2012).

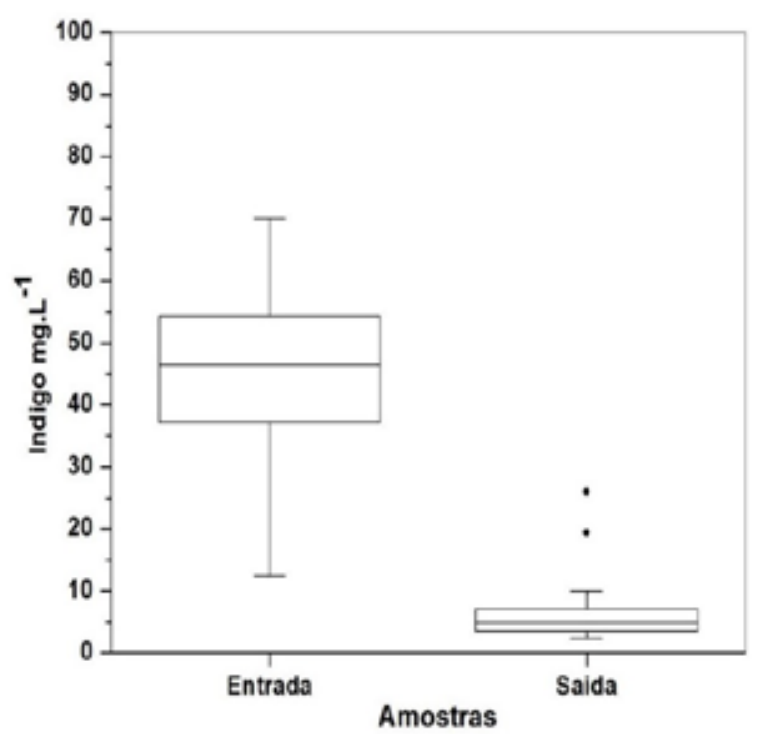

Figura 3 - Concentração de corante na entrada e saída do reator biológico.

O ensaio de adsorção no meio suporte (espuma de poliuretano) revelou que o material foi capaz de adsorver 40,75 mg de corante. Com relação ao ensaio de adsorção de corante na biomassa após a finalização do experimento, mostrou que a biomassa foi capaz de adsorver 96,85 mg de corante. Assim, o total de massa de corante na entrada do reator foi de $14728,22 \mathrm{mg}$, descontando o montante retido no meio suporte (40,75 mg) e o da biomassa $(96,85$ $\mathrm{mg}$ ); sendo a massa total na saída de $2188,64 \mathrm{mg}$, obteve-se uma eficiência de $85 \%$.
A exemplo disso, Anastasi et al. (2011) avaliaram a remoção de corantes ácidos e reativos de efluentes simulados e reais de uma tinturaria, utilizado o fungo Bjerkandera adusta num tempo reacional de 7 dias, e verificaram que o fungo suportou concentrações de corantes de até $5000 \mathrm{mg} \cdot \mathrm{L}^{-1}$, tendo alcançado percentuais de descoloração acima de $96 \%$ para esta concentração, como verificado nesta pesquisa.

Tan et al (2014), também estudando descoloração com fungo, verificaram que o corante Acid Red B foi degradadopelo fungo Magnusiomyces ingens com células suspensas e imobilizadas em alignato de cálcio. Os resultados obtidos mostraram que o fungo utilizado foi capaz de descolorir mais de $98 \%$ do Acid Red B em um tempo de $12 \mathrm{~h}$ para uma concentração de 50 mg.L-1. No entanto, as descolorações com células imobilizadas para a mesma concentração de Acid Red B foram de $95 \%$ no tempo de 7 h durante 15 ciclos. Esse estudo demonstra que é mais vantajoso usar fungos imobilizados, pois se pode reutilizar a mesma biomassa e a degradação de corante ocorre em um tempo menor do modo como foi feito nesta pesquisa.

A fim de verificar o mecanismo de degradação do corante, foram realizadas as varreduras de 200$1000 \mathrm{~nm}$, em espectrofotômetro, onde se pode observar o decaimento dos picos de absorbância do corante e formação de novos compostos e remoção da banda correspondente ao grupo cromóforo do corante (Figura 4).

A diminuição da banda correspondente ao grupo cromóforo, compreendida entre 400-700 nm (região do visível), em todos os ciclos, mostra a capacidade do fungo de utilizar as substâncias presentes no efluente como fonte de carbono e, por consequência, produzir um efluente clarificado, como pode ser visualizado na Figura 5. Ainda nesse contexto, pode-se observar que as substâncias compreendidas entre $200-400 \mathrm{~nm}$ (região do invisível) foram mineralizadas eficazmente e que não houve formação de subprodutos proveniente do metabolismo do fungo. 


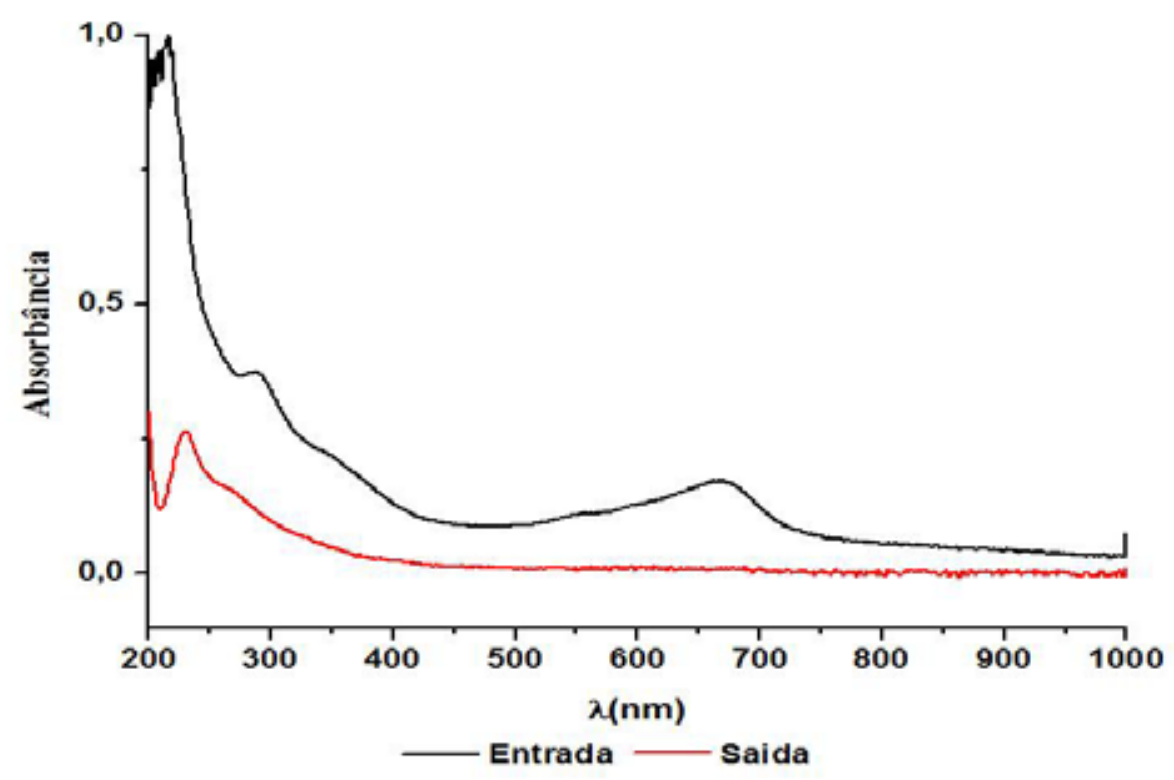

Figura 4 - Varredura feita no afluente e efluente do reator biológico da coleta 15.

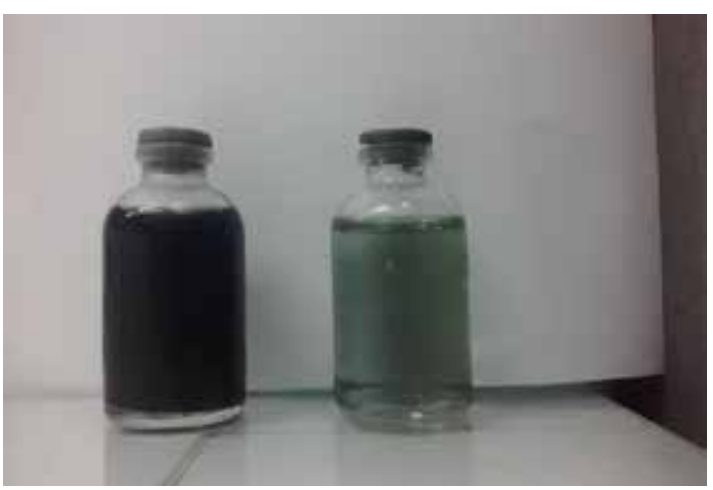

Figura 5 - Amostra da água residuária a 75\% preparada para entrada no reator à direita e amostra da saída do efluente tratado no reator de leito fixo e fluxo contínuo num TDH de $12 \mathrm{~h}$.
De acordo com Asad et al. (2007), a descoloração de corantes pode ser devido à adsorção, processo reversível, ou ao catabolismo do corante nas células do micro-organismo. Não foi observado aumento de concentração de corante no efluente final, podendo-se inferir que o principal mecanismo de degradação foi o catabolismo do corante pelo fungo utilizado nesta pesquisa.

$\mathrm{Na}$ Figura 6 e 7 estão apresentadas as variações das concentrações de DQQ total e solúvel com eficiência média de remoção de $88 \% \pm 6,09$ e de $87,63 \% \pm 5,97$, respectivamente. 


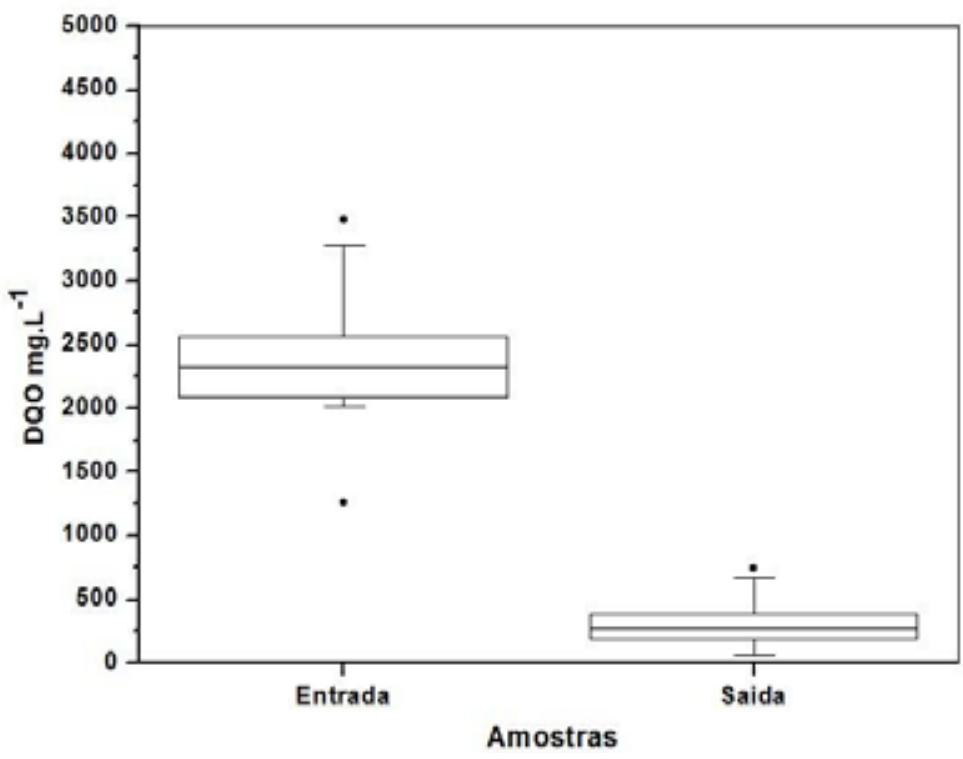

Figura 6- Concentração de DQQ total no reator biológico no TDH de $12 \mathrm{~h}$.

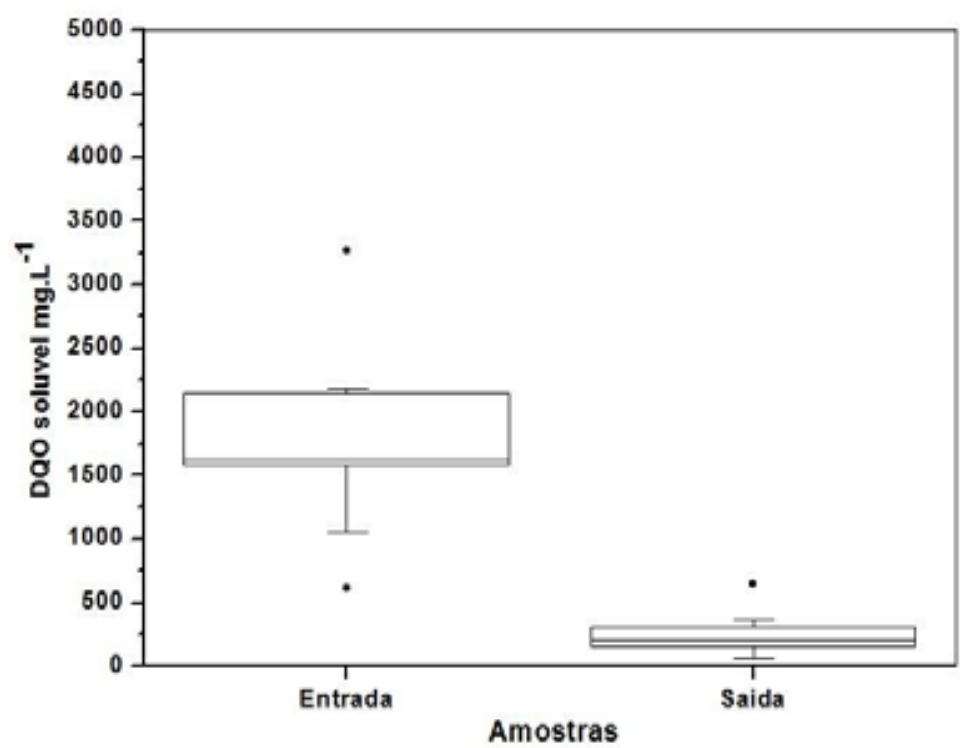

Figura 7- Concentração de DQQ solúvel no reator biológico no TDH de $12 \mathrm{~h}$.

Gajera et al (2015) estudaram a capacidade dos fungos Aspergillus níger Hypocrea koningii na remoção de matéria orgânica de dois efluentes coletados de uma indústria têxtil da área de Jeptur (dis. Junagadh, estato: Gujarat, India). Os autores utilizaram $800 \mathrm{~mL}$ em frascos do efluente acrescido de $8 \mathrm{~g}$ de peptona e $32 \mathrm{~g}$ de glicose e $5 \mathrm{~mL}$ de fungo mantiveram em skaker durante 12 dias e verificaram que a DQO do efluente $1\left(1994 \pm 20,3{\left.\mathrm{mg} . \mathrm{L}^{-1}\right)}^{-1}\right.$ teve uma diminuição de $60 \%$ e $50 \%$ quando inoculados com H.koningii e A.niger, respectivamente.
O efluente 2 (1949 $\left.\pm 18,3 \mathrm{mg} \cdot \mathrm{L}^{-1}\right)$ foi de $63 \%$ e $54 \%$ de remoção quando inoculados com H.koningii e A.niger, respectivamente. Esses percentuais foram inferiores aos verificados nesta pesquisa.

Patel e colaboradores (2013) estudaram a capacidade do fungo Myceliophthora vellerea HOQ871747, na remoção de DQO em um reator leito fixo contendo o corante reactive blue 220. Os autores obtiveram eficiência de $80-90 \%$ e foi observada formação de ácidos depois de $96 \mathrm{~h}$ de incubação. 
$\mathrm{O} \mathrm{pH}$ do afluente do reator desta pesquisa tinha o seu valor ajustado para $5 \pm 0,05$ em todas as fases, no momento de sua preparação, pois efluente in natura coletado apresentava $\mathrm{pH}$ com média superior a 9. A maioria dos fungos filamentosos junto com os fungos da podridão branca cresce em $\mathrm{pH}$ ácido, e dependendo do substrato utilizado o $\mathrm{pH}$ muda durante o cultivo (PATEL et al.,2013). O pH dos efluentes das coletas estudados era levemente ácido a alcalino, variando entre 6,09 a 7,89.

Com relação às frações nitrogenadas, representadas por amônia e nitrato, os dados estão apresen- tados nas Figuras 8 e 9 , respectivamente. O fungo Phanerochaete chrysosporium tem seu metabolismo influenciado pela concentração de nitrogênio no meio. Portanto, a fonte de nitrogênio foi proveniente somente do efluente in natura coletado, sem nenhuma outra adição de nitrogênio.

Em relação ao nitrato (Figura 8), é importante mencionar que, pelo método adotado, as concentrações do mesmo encontraram-se abaixo do nível de detecção. Assim, o reator obteve eficiência máxima durante todo o tempo de estudo para a utilização do nitrato.

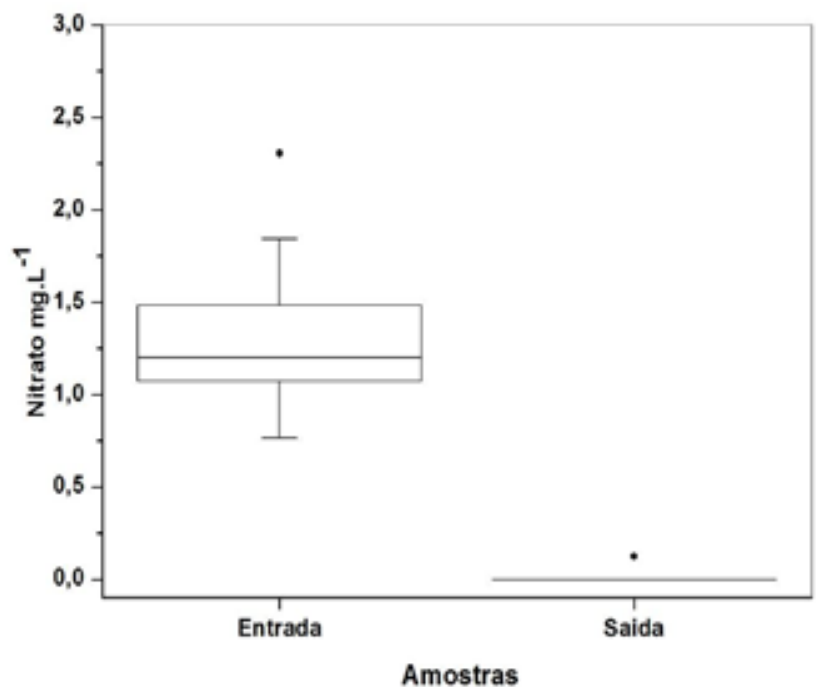

Figura 8- Concentração de nitrato no reator biológico no TDH de 12h.

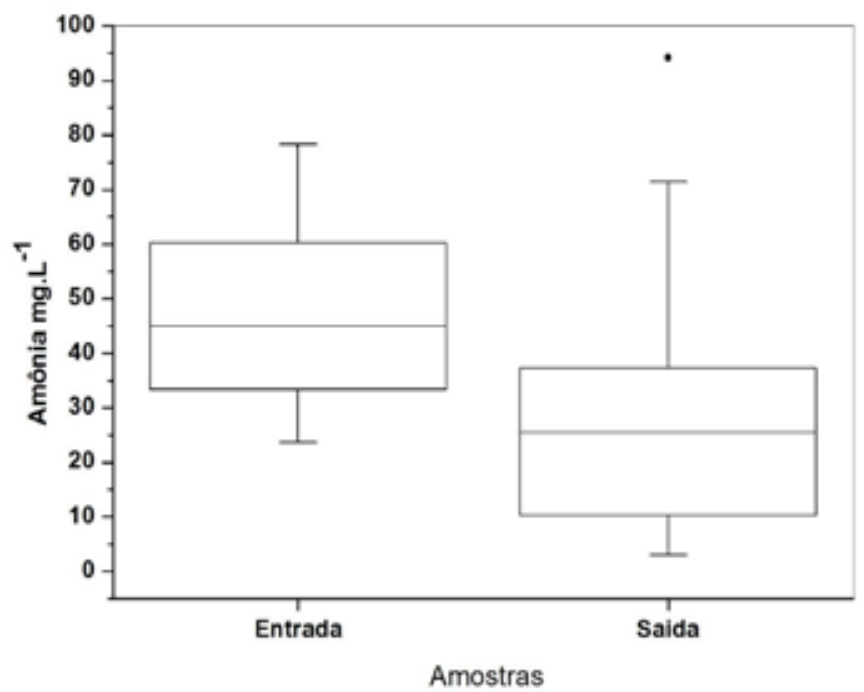

Figura 9 - Concentração de amônia no reator biológico no TDH de 12h. 
Anastasi et al. (2010) estudou a capacidade de 25 fungos basidiomicetos de 17 espécies diferentes na descoloração de nove corantes industriais selecionados por sua recalcitrância para biodegradação em sistemas convencionais de tratamento de efluentes têxteis, na concentração de 200 mg. $\mathrm{L}^{-1}$ com meios contendo diferentes concentrações de fontes de carbono e nitrogênio. Com exceção de um fungo da espécie Bjerkandera, o melhor meio para a descoloração dos corantes foi o meio com menor concentração de nitrogênio.

Desde os primeiros estudos sobre Phanerochaete chrysosporium sabe-se que a depleção de nutrientes, incluindo a fonte de nitrogênio utilizável, desencadeia a produção do sistema ligninolítico e, portanto, o potencial de degradação de fungos, mas o excesso de nitrogênio suprime o seu sistema lignolítico (KAAL et al.1995). Portanto, pode-se concluir que os compostos nitrogenados presentes no efluente desta pesquisa não inibiram o sistema lignolítico e, portanto, não afetaram a degradação dos corantes presentes no efluente têxtil.

No tocante à contagem de colônias dos micro-organismos, no final da operação do reator, esta foi de 90000 UFC. $\mathrm{mL}^{-1}$ e de 21000 UFC. $\mathrm{mL}^{-1}$, respectivamente, em relação ao número de colônias fúngicas e de bactérias, endossando a predominância da comunidade fúngica no reator biológico.

Vale ressaltar que a pesquisa, ao utilizar efluente in natura, não visa à operação do reator em condições assépticas ao longo de todo o processo de tratamento, pois a interação entre fungos e bactérias é benéfica ao processo, pois atuam em consórcio, também, na natureza.

\section{CONCLUSÕES}

O fungo Phanerochaete chrysosporium imobilizado em reator contínuo de fluxo ascendente mostrou-se eficiente na degradação do corante e de DQO do efluente têxtil in natura diluído a $75 \%$.
O fungo mostrou-se capaz de utilizar as fontes de nitrogênio presentes no efluente in natura, principalmente nitrato, e amônia foram superior a $50 \%$.

A contagem de micro-organismos no reator biológico mostrou predominância de fungos sobre a de bactérias.

\section{REFERÊNCIAS}

APHA. Standard Methods for Examination of Water and Wastewater. 20a edição. American Water Work Association, Water Enviroment Federation. Washington. p 953.2005.

ALMEIDA, D.; SILVA, M.; MIRANDA, R.; MACIEL, C.; GUSMÃO, N. Descoloração do corante índigo carmim e produção de lacase por fungos filamentosos. Scientia Plena, v. 8, n. 5.2012.

ANDRADE, M.V.F. Biodegradação de corante têxtil por uso de reator biológico em batelada sequenciais com biomassa imobilizada de Phanerochaete chrysosporium. 2013. Dissertação (Mestrado em Tecnologia em Gestão Ambiental). Instituto Federal de Educação Ciência e Tecnologia do Ceara. Fortaleza. 2013.

ANASTASI, A.;PARATO, B.; SPINA, F.; TIGINI, V.; PRIGIONE, V.; VARE$\mathrm{SE}, \mathrm{C}$. Decolourization and Detoxification in the fungal treatment of textile wastewaters from deying processes. New Biotechnology, v. 29, n. 01, p. 38-45.2011.

ANASTASI, A.;PRIGIONE,V.;VARESE,G.C.Industrial dye degradation and detoxification by basidiomycetes belonging to different eco-physiological groups. Journal of Hazardous Materials,v. 177, p. 260-267.2010.

ASAD, S.;AMOOZEGAR, M.A.;POURBABAEE, A.A.; SARBOLOUKI, M.N.; DASTGHEIB, S.M.M. Decolorization of textile azo dyes by newly isolated halophilic and halotolerant bacteria. Bioresour. Technol. v.98, p.2082-2088.2007.

BOZIC, M.;KOKOL V. Ecological alternatives to the reduction and oxidation processes in dyeing with vat and sulphur dyes. Dyes and Pigments,v.76,p.299-309.2008.

CHANDER, M.; ARORA, D. S. Evaliation of some white-rot fungi for their potential to decolourise industrial dye. Dyes and Pigments, v. 72 , n. 2, p. $192-198.2007$.

COUTO, S.R. Dye removal by immobilised fungi. Biotechnology Advances,v. 27 ,p. 227-235.2009.

FRANCA,R.D.G.;VIEIRA,A.;MATA,A.M.T.;CARVALHO,G.S.;PINHEIRO,H.M.;LOURENÇO,N.D. Effect of an azo dye on the performance of an aerobic granular sludge sequencing batch reactor treating a simulated textile wastewater. Water Research,v.85,p.327-336,2015. 
FOURCAUDE, F., DELAWARDE, M., GUIHARD, L., NICOLAS, S., AMRANE, A.Electrochemical Reduction Prior to Electro-Fenton Oxidation of Azo Dyes: Impact of the Pretreatment on Biodegradability. Water, Air, \& Soil Pollution, v. 224, p.1385-1395.2010.

GAJERA, H.P., BAMBHAROLIA,R.P., DARSHNA ,H.G.,PATEL, S.V., GOLAKIYA,B.A.Molecular identification and characterization of novel Hypocrea koningii associated with azo dyes decolorization and biodegradation of textile dye effluents. Process Safety and Environmental Protection ,v.9 8,p. 406-416.2015.

GHALY, A.E.; ANANTHASHANKAR, R.; ALHATTAB, M.V.V.R. Production, characterization and treatment of textile effluents: a critical review. J. Chem. Eng. Process Technol,v. 5,p. 1-18.2014.

GIARDINA P, FARACO V, PEZZELLA C, PISCITELLI A, VANHULLE S, SANNIA G. Laccases: a never-ending story. Cell. Mol. Life Sci. v.67,p.369-385,2010.

KAAL ,E.J.; FIELD ,J.A.; JOYCE, T.W. Increasing ligninolytic enzyme activities in several white-rot basidiomycetes by nitrogen sufficient media, Biores. Technol,v. 53,p. 133-139.1995.

KAMIDA, H. Biodegradaçao de Efluente têxtil por Pleurotus sajor-caju. Quim. Nova, v. 28, n. 4, p. 629-632, 2005.

KANG,S.F.;YEN, H.-Y.;LIAO, C.-H.;YAO, Y.-C. Decolorization and mineralization of textile effluent by $\mathrm{H} 2 \mathrm{O} 2 / \mathrm{ultraviolet}$ processes. Environ. Eng. Sci,v. 27,p. 357-363,2010.

KANT, R. Textile dyeing industry an environmental hazard. Nat. Sci,v.4, p.22-26.2012.

KAPDAN, I.K.,KARGI, F., MCMULLAN, F.Effect of environmental conditions on biological decolorization of textile dyestuff. Enzyme and Microbial Technology, v. 26, p. 381-378.2000.

KAUSHIK, P.,MALIK, A. Fungal dye decolourization: recent advances and future potential. Environment International,v. 35, p.127141.2009.

OZDEMIR, S.,CIRIK, K., AKMAN, D., SAHINKAYA, E., CINAR, O.Treatment of azo dyecontaining synthetic textile dye effluent using sulfidogenic anaerobic baffled reactor. Bioresour. Technol,v. 146,p. 135-143.2013.
PATEL,V.R.,BHAAT,N.S.,BBHATT,H. Involvement of ligninolytic enzymes of Myceliophthora vellerea HQ871747 in decolorization and complete mineralization of Reactive Blue 220. Chemical engineering journal. v.233, p. 98-108.2013.

QU, Y.; SHI, S.; MA, F.; YAN, B. Decolorization of reactive dark blue $\mathrm{K}-\mathrm{R}$ by the synergism of fungus and bacterium using response surface methodology. Bioresour. Technol,v. 101, p.8016-8023,2010.

RODRIGUES, K. A.; SILVA, K. M. L.; MARINHO, G. M.; LIMA, P. C.; PESSOA WANDERLEY, C. R.; SILVA, G. M. Remoção de corante por uso de Aspergillus niger AN400 em reator em bateladas sequenciais. Química Nova Vol. 34 no 7. São Paulo.2011.

RODIER, J. L'analyse de l'eau: eaux naturelles, eaux résiduales, eaux de mer. Volume 1, 5ed. Dunod (Ed.) Paris. 1975.

RODRIGUES, K. A.; SILVA, K. M. L.; MARINHO, G. M.; LIMA, P. C.; PESSOA WANDERLEY, C. R.; SILVA, G. M. Remoção de corante por uso de Aspergillus niger AN400 em reator em bateladas sequenciais. Química Nova Vol. 34 nº 7. São Paulo. 2011.

RODRIGUES, K. A. Uso de reatores biológicos com fungos para remoção de fenol de água residuária sintética. 2006. 145f. Tese (Doutorado em Saneamento) - Escola de Engenharia de São Carlos da Universidade de São Paulo, São Carlos, 2006.

SOLÍS, M.,SOLÍS,A.,PÉREZ,H.I.,MANJARREZ,N.,FLORES,M. Microbial Decolouration of Azo Dyes: A Review. Process Biochemistry, v.47 ,p.1723-1748.2012.

TORTORA, G.J., FUNKE, B.R., CASE, C.L. Microbiology: an introduction, 6.ed. Porto Alegre, 827 pp. 2000.

TAN,L.,LI,H.,NING,S.,XU,B. Aerobic decolorization and degradation of azo dyes by suspended growing cells and immobilized cells of a newly isolated yeast Magnusiomyces ingens LH-F1. Bioresource Technology. 158,p. 321-328.2014.

YANG,Q.,LI,C., LI.H., LI,H.Y. NING.(2009) Degradation of synthetic reactive azo dyes and treatment of textile wastewater by a fungi consortium reactor. Biochemical Engineering Journal.v. 43, p.225-230.2009. 